\title{
Erratum to: Materials Data Infrastructure and Materials Informatics
}

Joanne Hill, Arun Mannodi-Kanakkithodi, Ramamurthy Ramprasad, and Bryce Meredig

\section{Erratum to:}

Chapter 9 in: D. Shin, J. Saal (eds.), Computational

Materials System Design,

https://doi.org/10.1007/978-3-319-68280-8_9

In this chapter, the author has noticed error in the URL's provided. The updated table is as follows: 


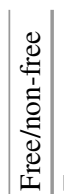

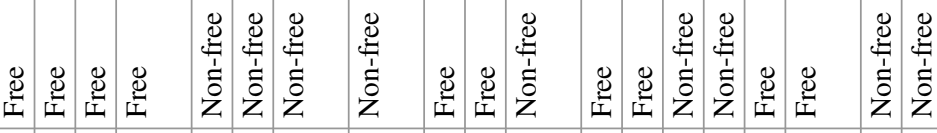

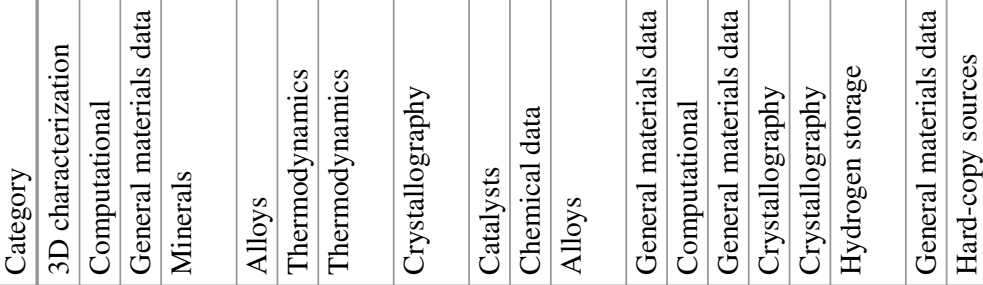

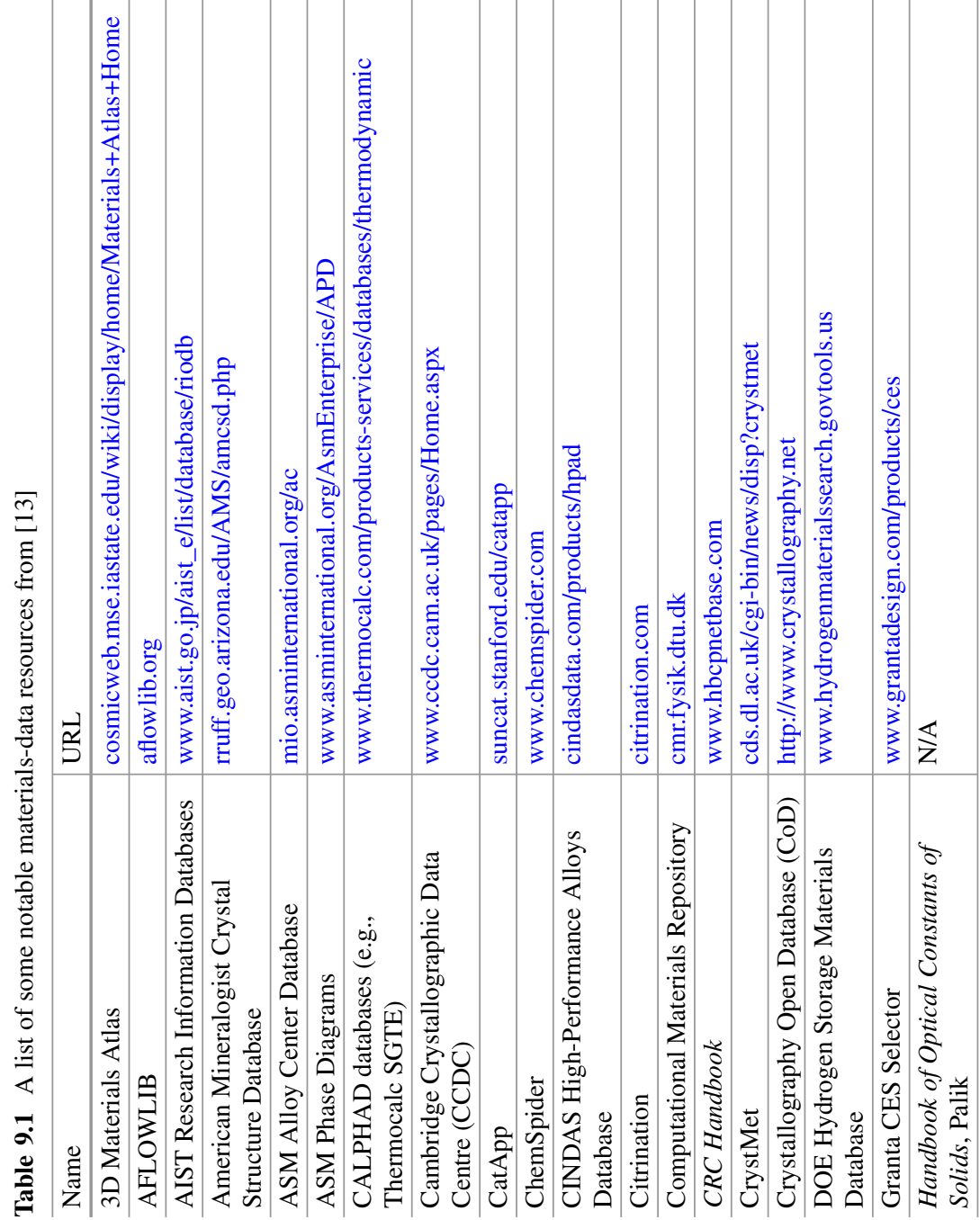




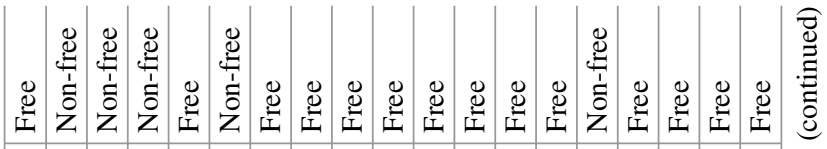

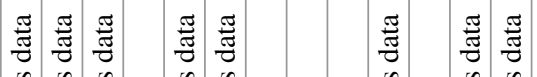
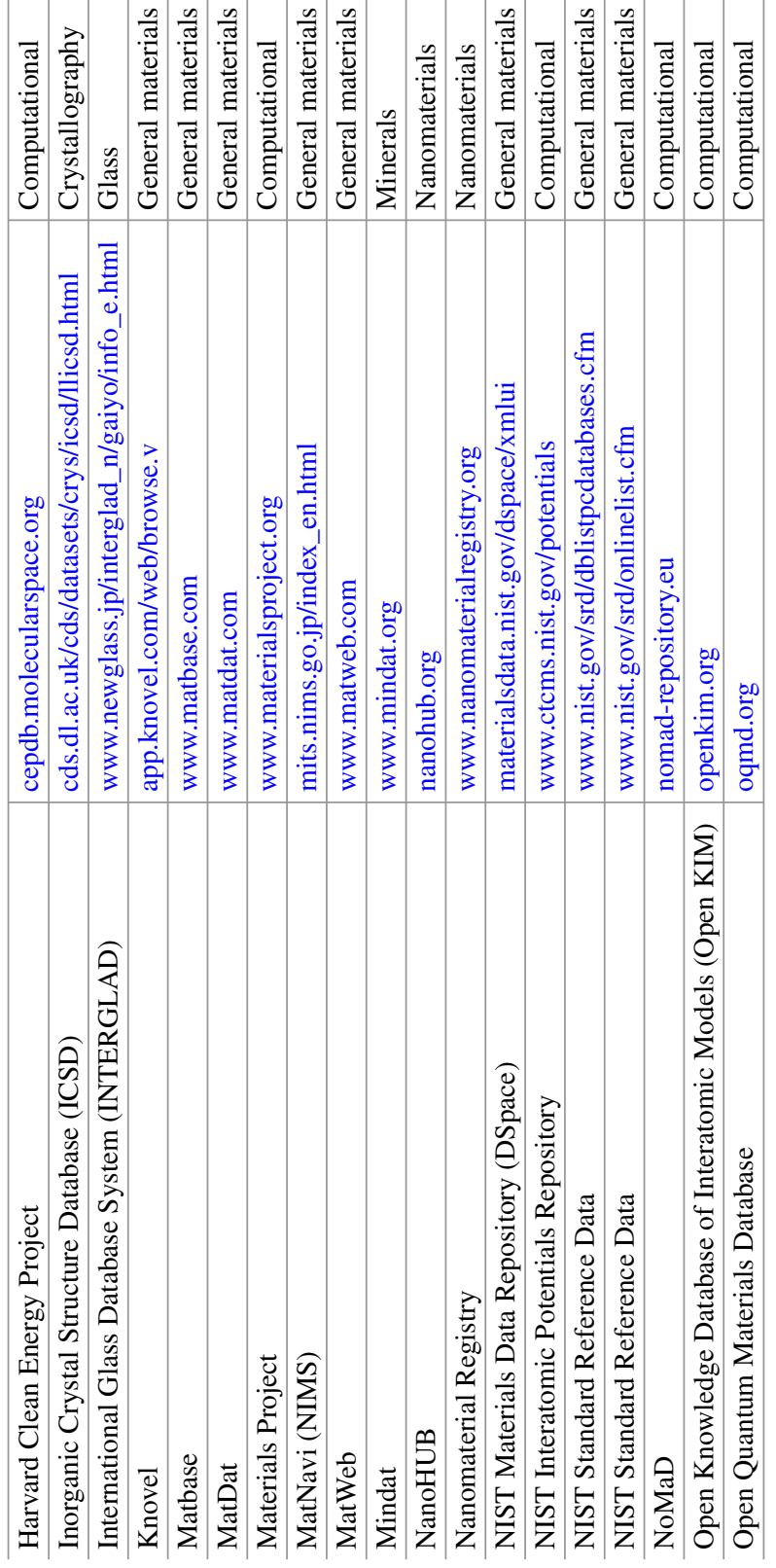

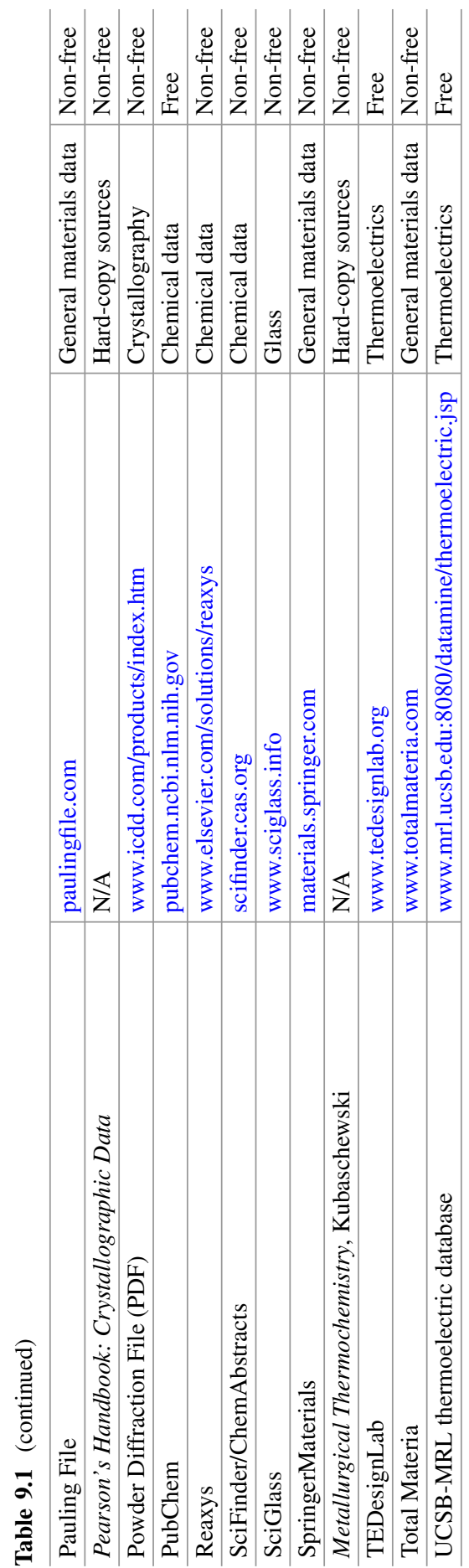